\title{
What Do Women Lose if They Are Prevented From Meeting Their Breastfeeding Goals?
}

Share this:

\author{
Amy Brown, $\mathrm{PhD}^{\mathrm{a}}$
}

This article explores the complex issue of breastfeeding and maternal mental health. Many women stop breastfeeding before they are ready, often leading to feelings of anxiety, guilt, and anger. Critics of breastfeeding promotion blame breastfeeding advocates for this impact, claiming that if the focus were merely on feeding the baby, with all methods equally valued and supported, maternal mental health would be protected. Established health impacts of infant feeding aside, this argument fails to account for the importance of maternal breastfeeding goals, or the physical and emotional rewards breastfeeding can bring. Although some women will take comfort in the message that what matters most is that the baby is fed, others view such suggestions as a lack of recognition of their wishes and the loss that they feel, exacerbating their grief and frustration. The purpose of this article is to highlight the importance of recognizing and valuing women's individual breastfeeding goals, and not dismissing or invalidating their experience if they do not meet these by telling them that they do not matter. To move forward, we must recognize the impact of all infant feeding experiences, consider the impact of public messaging, and work to support more women to meet their goals.

Keywords: breastfeeding; postnatal depression; breastfeeding goals; maternal identity; emotions; pleasure; bonding; pride

The relationship between infant feeding experiences and maternal mental health is never far from our thoughts. Between news headlines, social media debates, and our own personal and professional experiences with mothers, we are very aware that infant feeding experiences matter, not just for health but for psychological well-being too.

\section{Breastfeeding and Women's Mental Health}

Numerous research studies over the last few decades have shown us that exclusive breastfeeding protects maternal mental health (Dennis \& McQueen, 2009; KendallTackett, Cong, \& Hale, 2011; Ystrom, 2012). But the relationship between breastfeeding and maternal mental health is complex. Women who have good mental health may find their breastfeeding experience easier to navigate, while mothers who are struggling may find breastfeeding, or caring for a baby in general, more challenging. Mothers who are experiencing depression are more likely to perceive their infants as difficult (when independent reviewers do not) (Gonidakis, Rabavilas, Varsou, Kreatsas, \& Christodoulou, 2008) and are less likely to be responsive with their infants. They may miss cues and be less sensitive with attachment and positioning (Bigelow, Power, MacLellan-Peters, Alex, \& McDonald, 2012), which we know can damage breastfeeding (Brown \& Lee, 2013).

a. a.e.brown@swansea.ac.uk
Of course, the opposite also plays out. A woman's experience of feeding her baby can affect her well-being. If a woman plans to breastfeed and is then unable or she cannot meet her breastfeeding goals, her risk of depression increases (Borra, Iacovou, \& Sevilla, 2015; Gregory, Butz, Ghazarian, Gross, \& Johnson, 2015). If a woman experiences pain and difficulties, this again is associated with a higher risk of depression (Brown, Rance, \& Bennett, 2016). Although some mothers may find peace with their decision to stop, ending a breastfeeding relationship before she is ready can lead to a whole spectrum of emotions including grief, anger, loss, and decreased confidence and feelings of failure as a mother (Fahlquist, 2016; Lee, 2007; Taylor \& Wallace, 2012). This can be exacerbated by a drop in protective breastfeeding hormones (such as oxytocin and prolactin), which enhance feelings of calm and relaxation (Gallup, Nathan Pipitone, Carrone, \& Leadholm, 2010).

Unfortunately, significant numbers of women are not meeting their breastfeeding goals. In the UK, $80 \%$ of women who stop breastfeeding in the first 6 weeks report that they were not ready to do so, with pain, difficulty, and a lack of support given as the most common reasons for doing so (McAndrew et al., 2012). Similar patterns are seen in the USA, Canada, and Australia (Brown, Dodds, Legge, Bryanton, \& Semenic, 2014; Li, Fein, Chen, \& Grummer-Strawn, 2008; Newby \& Davies, 
2016), leaving many women potentially at risk of these emotions and mental health difficulties. Consequently, women often report that they feel significant pressure to breastfeed, while support to do so is inadequate (Andrews \& Knaak, 2013; Craig \& Dietsch, 2010; Thomson, Ebisch-Burton, \& Flacking, 2015).

\section{Women Deserve More Than the Bottom Line}

Based on this, the argument that we see played out across the media often centers on the suggestion that there is too much pressure on women to breastfeed, and to protect maternal health we should instead take a more mothercentered approach, promoting all feeding options as equal. The focus should be on ensuring a baby is fed, with the proposition that anything else is just noise, with minimal real impact upon mother and baby. Criticisms have been made of the lactation field, predominantly by those with a social sciences background, with accusations of "militant lactivism" destroying women's mental health. Breastfeeding is posed as something that is a moral, identifying signaling behavior as against anything that impacts upon health (Faircloth, 2013; Jung, 2015; Lee, Bristow, Faircloth, \& Macvarish, 2014; Wolf, 2010). The call to stop promoting breastfeeding from certain sectors is strong.

However, although this may provide comfort for some, taking this approach for all is akin to treating the symptoms rather than taking a deeper exploration of their cause. Women who have no desire to breastfeed do not experience a negative impact on their mental health when they do not breastfeed (Pope, Mazmanian, Bédard, \& Sharma, 2016). Instead, negative emotions are typically a consequence of intentions and desires not being met. Simply telling women that the most important thing is that their baby is fed, may work for some, but can be interpreted by others as that their experience does not matter, worsening their grief as they feel that their goals are being brushed aside.

The notion of telling a woman to focus on the positive rather than what she has lost is a theme that runs throughout pregnancy, birth, and mothering. Women who miscarry are often told "Next time; it wasn't meant to be." Women who have traumatic births are told "the main thing that matters is that you have a healthy baby." Increasingly women are now being told that "the main thing that matters is your baby is being fed." Of course, on a bottom-line basis, these things are true. A healthy, fed baby is at the top of women's wishlists.

However, we owe it to women to give them more than the bottom line. It is now accepted that a traumatic birth can have long-lasting psychological and physiological impacts upon a woman and it is important to enhance the experience where possible (Elmir, Schmied, Wilkes, \& Jackson, 2010), but what about breastfeeding? Telling women that the main thing that matters is that their baby is fed may provide comfort for some but for others, it can feel that their wishes, their expectations, what they perceived to be normal functioning for their body, are being invalidated and dismissed.

\section{Why Do Many Women Want to Breastfeed So Much?}

To understand the importance of not dismissing women's breastfeeding concerns, we must look at what breastfeeding means to many mothers, and why they want to breastfeed. Public health literature would state that women should be encouraged to breastfeed because breastfeeding is protective of infant and maternal health (Bartick et al., 2017; Ip, Chung, Raman, Trikalinos, \& Lau, 2009). However, this reasoning is only a small part of why breastfeeding is so important to women with women describing a whole host of psychological benefits they feel (Brown \& Lee, 2011; Knaak, 2010). Of course, not all women wish to breastfeed (Brown et al., 2014; Li et al., 2008; McAndrew et al., 2012; Newby \& Davies, 2016), but as noted previously, these women are typically happy with that choice (Pope et al., 2016). This debate is not about those women; it is about how we can better support women who want to breastfeed but cannot.

\section{Breastfeeding Is a Biologically Normal, Instinctive Behavior That Women Expect to Be Able to Do}

Questioning why women want to breastfeed is illogical in as far as we do not question why human beings wish to use any other function that their body was designed for. Women describe an urge to breastfeed as something that is instinctual; physically, in that their body produces milk without their choice, and emotionally, in that women often cannot describe why they so strongly want to breastfeed, they just do (Díaz Meneses, 2013; LööfJohanson, Foldevi, \& Rudebeck, 2013).

Breastfeeding is a natural stage of childbirth. The infant is born, the placenta is delivered, and the infant will expect to be fed. Infants are biologically programmed to maneuver themselves to the breast (Henderson, 2011), and the breast sends signals-secretions-for the infant to find its way there (Righard et al., 1990). At this early stage, breast milk production and the infant urge to breastfeed is a normal, hormonally driven bodily function, not a choice that is made (Neville, Morton, $\mathbb{\&}$ 
Umemura, 2001). This, of course, is not to be confused with biological determinism. Just because women are "designed" to breastfeed their babies after birth does not mean they are required to, from a sociocultural perspective. However, at birth, their body has not recognized the wider social context, and prepares for a baby to be fed.

Many women who want to breastfeed describe how they always knew that they would try. They were, of course, aware of other options, but simply, they never considered any other option for themselves (Brown \& Lee, 2011; Hegney, Fallon, \& O’Brien, 2008; Knaak, 2010). Others describe an indescribable urge that occurred at birth, despite no antenatal intention-evidenced by a small but significant group of women who make their decision to breastfeed at birth (McAndrew et al., 2012). Moreover, women have an understandable expectation they will be able to breastfeed. One of the biggest emotions women face when they cannot breastfeed is a shock that their body did not work as expected (Brown, 2016). Other emotions experienced-grief, anger, loss-all reflect women's desire to engage in biologically normal behavior.

We do not present other normal physiological behaviors as an option equal to medical involvement. Take breathing apparatus, kidney dialysis, mobility supportwe highly value that option when needed. It can be lifesaving and life-enhancing. However, we do not question why individuals would want to breathe, filter, or move of their own accord. We recognize the emotional impact that this dysfunction can bring, rather than inferring it does not matter. Empowering women to follow this natural, instinctual function, and supporting them if they cannot is therefore vital.

\section{Breastfeeding Is Viewed as a Central Part of Becoming a Mother}

Breastfeeding and the concept of maternal identity go hand in hand. Breastfeeding is often part of what women envisage themselves doing as a mother. Women report seeing breastfeeding as a way of identifying with a type of mother they wish to be, to fulfill what they see as a maternal physiological role. It is not simply about milk transfer, but a mothering tool, one helping to enhance bonding and closeness. It is a relationship and an experience, rather than simply a nutritional means (Brown, 2016; Burns, Fenwick, Sheehan, \& Schmied, 2013). Breastfeeding can be a way of healing after a birth that did not go to plan, or a way of protecting their infant especially if they are sick (Lööf-Johanson et al., 2013; Marshall, Godfrey, \& Renfrew, 2007). This experience can be particularly stark in mothers of preterm infants. Breastfeeding is a fulfilling way of healing, bonding, and part of claiming maternal "ownership" of the infant away from machines and staff (Davim, Enders, \& Silva, 2010; Flacking, Ewald, Nyqvist, \& Starrin, 2006).

However, women are increasingly told that formula milk is a comparable substitute for breastfeeding. Formula milk is a safe and sufficient product, which can be lifesaving in the absence of breast milk. However, placing any scientific comparison of the content of breast and formula milk aside, formula-feeding is not a direct substitute for breastfeeding. Although some women may report that they find the process more convenient, or that it is reassuring to be able to see how much milk the baby is consuming (Brown, Raynor, \& Lee, 2011a), other women will feel that they lose something through the process of not being able to breastfeed their infant. When women who want to do so cannot mother in this way, they grieve-for the loss of breastfeeding but also whom they envisaged themselves to be (Robinson, 2016). Palmer et al. describes this as an "existential lostness" (Palmér, Carlsson, Mollberg, \& Nyström, 2012).

Critics of this relationship have suggested that mothers have become too overly invested in mothering, viewing breastfeeding as a way to signal to others that they are "good" and "moral" mothers (Faircloth, 2010; Ryan, Bissell, \& Alexander, 2010). This need has been portrayed as disempowering (Crossley, 2009) and as symbolic of overall pressure on women to behave in a certain way dictated by societal, gendered, and moral norms (Shaw, 2004). However, this is in direct contrast to many women's experiences who describe breastfeeding as fulfilling (Davim et al., 2010) and empowering (Schmied \& Barclay, 1999). If women wish for something biologically normal to be part of their identity as a mother, why should this be criticized? It is not saying that all mothers should feel this way, or that mothers who do not breastfeed are less of a mother. Where does this feeling come from and how we can prevent it from happening, while simultaneously allowing those women who are breastfeeding to hold it as part of their identity?

\section{Maternal Rewards: Pride, Pleasure, and Achievement}

An almost unspoken factor when considering the loss of a breastfeeding experience is the loss of the positive factors breastfeeding can bring to the mother. Breastfeeding is often posed as for the infant, where in fact it is a mutually beneficial relationship. Physiologically mothers experience reductions in risk across reproductive cancers, heart disease, and diabetes if they breastfeed. However, although mothers will often cite these reasons for deciding to breastfeed, a successful breastfeeding 
experience can bring forth a whole host of positive and personal rewards (Brown \& Lee, 2011; Knaak, 2010).

Breastfeeding can be a source of intimacy and feeling connected (Battersby, 2008; Schmied \& Lupton, 2001). Breastfeeding can be a great source of pride, especially if she has overcome challenges (Brown \& Lee, 2011; Shepherd, Walbey, \& Lovell, 2017). Breastfeeding can be a pleasurable experience, especially once mothers move past those early days and weeks when the dyad are mastering the skill (Lööf-Johanson et al., 2013; Schmied \& Barclay, 1999). Breastfeeding can also bring about a personal sense of achievement, feeling like something mothers have "got right," especially if they have had a difficult birth (Hall \& Hauck, 2007; Manhire, Hagan, \& Floyd, 2007).

Of course, all of these connotations give fuel to the common criticism that mothers, especially when they breastfeed past infancy or in public (Daglas \& Antoniou, 2012), are simply "doing it for themselves." This is nonsensical, and globally many infants breastfeed into the third year and beyond (Victora et al., 2016). However, how much of this disdain is clouded by wider views of women and the female body? In what comparative way would men face the accusation that if they experienced pleasure from a reproductive function, or had a part of their body that wasn't working correctly that they wanted to be fixed, that they were simply doing it for themselves or being selfish?

Take a comparator of male sexual organ dysfunction, erectile dysfunction. Albeit involving a primary rather than secondary sexual characteristic, the equivalent argument of "simply doing it for yourself" and a lack of research into dysfunction would not occur. Numerous research studies have explored the impact of erectile dysfunction upon the quality of life, depression, and anxiety, with specific tools developed to measure its psychological impact (Latini et al., 2002; Soterio-Pires et al., 2017) and satisfaction with treatment (Althof et al., 1999). Investment in research and treatment for the condition is vast, with 9 billion dollars spent globally on prescriptions each year (Cockerell, 2015). Five times as much research is conducted into erectile dysfunction than research into premenstrual syndrome and dysphoric disorder, despite this affecting five times as many women than men (Cockerell, 2015). Male bodily dysfunction is recognized as significant, important, and worth investing in, rather than persuading men that it does not matter.

\section{Clinical Implications: The Way Forward}

For many women, aside from being a normal biological function that should not have to be defended, a successful breastfeeding experience can be protective of both physiological and psychological health. However, we know that many women are not part of this experience, and instead, are being left with a web of complex negative memories and emotions. Breastfeeding promotion remains a public health priority, but we must do more to understand and protect women who have not been able to meet their breastfeeding goals.

Proponents of the "fed is best" argument uphold the idea that removing discussion of the importance of breastfeeding (or creating an equal platform for all feeding options) would reduce the number of women negatively affected by their infant-feeding experiences. This may work for some, and it is important that research explores those experiences in more depth. However, for others, the literature strongly calls this into question.

Not all negative emotions around stopping breastfeeding are driven by the concept of "militant lactivists" supposedly casting shame upon women who not breastfeed. Women themselves want to breastfeed for reasons other than health. They talk about the feelings of loss they experience, while women who have been able to meet their goals talk about the feelings of connectedness and pride they feel. Many women who wanted to breastfeed but were unable to feel a host of negative emotions precisely because they wanted to. Not because they were told to, but because their experience was important to them. Therefore, to make any real difference, we need to create a better environment for women to breastfeed in.

Breastfeeding decisions, just like emotions, are complex. Physiological impediments to breastfeeding do occur, although most impact upon the ability to produce sufficient milk rather than any milk at all (Lawrence \& Lawrence, 2001). However, the proportion of women experiencing breastfeeding challenges is significantly above this expected level (Brown et al., 2014; Li et al., 2008; McAndrew et al., 2012; Newby \& Davies, 2016). Women's ability to breastfeed is being affected by sociocultural factors in their environment (Brown, 2017), a statement supported by vastly differing durations of breastfeeding around the world (Victora et al., 2016). Issues such as disinvestment in health services, negative public attitudes, unsupportive family and friends, financial pressures, and inaccurate beliefs around breastfeeding and normal infant behavior can all cause challenges with breastfeeding that lead mothers to stop before they had planned, removing their choice and volition (Brown \& Arnott, 2014; Brown \& Harries, 2015; 
Meedya, Fahy, \& Kable, 2010; Renfrew, McCormick, Wade, Quinn, \& Dowswell, 2012; Rollins et al., 2016; Sriraman \& Kellams, 2016).

To move forward, we must invest in mothers. We may have breastfeeding promotion messages, but the support available for mothers is still lacking (Entwistle, Kendall, \& Mead, 2010; Schmied, Beake, Sheehan, McCourt, \& Dykes, 2011). Increased investment in breastfeeding support so that all women who want to breastfeed get the best possible chance to establish and maintain breastfeeding is vital. However, investment must go more widely than that, ensuring that we recognize and support all women based on their individual needs.

A primary focus of this must be more investment into understanding lactation complications in the first place. As Jennifer Grayson writes in her book Unlatched, "there are no tests" when it comes to lactation complications. In discussion with Professor Peter Hartmann, she explores how although a typical course of action, if you have a physiological health issue, is to visit a medic, the solution for many medics to a breastfeeding challenge is to give formula milk (Grayson, 2016). Public health bodies are raising expectations, but failing to support and protect mothers to breastfeed, or to have answers if they cannot. No wonder so much grief, hurt, and anger abounds.

We must also invest in practical and emotional support for women who have been unable to breastfeed. For some, this will be a practical support to bottle feed. Some will be comforted by the knowledge that the baby is getting fed. For others, their loss will be more complex. Miriam Labbok spoke eloquently about the concept of breastfeeding grief. Women who want to breastfeed but are unable to do so are not simply grieving the loss of a means of providing nutrition to their infant. They are grieving the loss of a relationship, a source of emotional fulfillment, and an identity. When people are grieving, we do not tell them that their hopes did not matter. Instead, we support them, as Labbok proposed to move through their grief by identifying it, feeling it, and working through it (Labbok, 2008).

Above all, we must stop telling women that their hopes and dreams when it comes to breastfeeding their baby do not matter.

\section{References}

Althof, S. E., Corty, E. W., Levine, S. B., Levine, F., Burnett, A. L., McVary, K., .. .Seftel, A. D. (1999). EDITS: Development of questionnaires for evaluating satisfaction with treatments for erectile dysfunction. Urology, 53(4), 793-799. http://dx.doi.org/ 10.1016/S0090-4295(98)00582-2
Andrews, T., \& Knaak, S. (2013). Medicalized mothering: Experiences with breastfeeding in Canada and Norway. The Sociological Review, 61(1), 88-110. http://dx.doi.org/10.1111/ 1467-954X.12006

Bartick, M. C., Jegier, B. J., Green, B. D., Schwarz, E. B., Reinhold, A. G., \& Stuebe, A. M. (2017). Disparities in breastfeeding: Impact on maternal and child health outcomes and costs. The Journal of Pediatrics, 181, 49-55. http://dx.doi.org/10.1016/j. jpeds.2016.10.028

Battersby, S. (2008). Discourse related to emotions and infant feeding. Emotions in Midwifery and Reproduction, Oct, 28.

Bigelow, A., Power, M., MacLellan-Peters, J., Alex, M., \& McDonald, C. (2012). Effect of mother/infant skin-to-skin contact on postpartum depressive symptoms and maternal physiological stress. Journal of Obstetric, Gynecologic $\mathcal{E}$ Neonatal Nursing, 41(3), 369-382. http://dx.doi.org/10.1111/j.1552-6909. 2012.01350.x

Borra, C., Iacovou, M., \& Sevilla, A. (2015). New evidence on breastfeeding and postpartum depression: The importance of understanding women's intentions. Maternal and Child Health Journal, 19(4), 897-907. http://dx.doi.org/10.1007/s10995-0141591-z

Brown, A. (2016). What do women really want? Lessons for breastfeeding promotion and education. Breastfeeding Medicine, 11(3), 102-110. http://dx.doi.org/10.1089/bfm.2015.0175

Brown, A. (2017). Breastfeeding as a public health responsibility: A review of the evidence. Journal of Human Nutrition and Dietetics, 30(6), 759-770. http://dx.doi.org/10.1111/jhn.12496

Brown, A., \& Arnott, B. (2014). Breastfeeding duration and early parenting behaviour: The importance of an infant-led, responsive style. PLoS One, 9(2), e83893. http://dx.doi.org/10. 1371/journal.pone.0083893

Brown, C. R., Dodds, L., Legge, A., Bryanton, J., \& Semenic, S. (2014). Factors influencing the reasons why mothers stop breastfeeding. Canadian Journal of Public Health, 105(3), 179-185. http://dx.doi.org/10.17269/cjph.105.4244

Brown, A., \& Harries, V. (2015). Infant sleep and night feeding patterns during later infancy: Association with breastfeeding frequency, daytime complementary food intake, and infant weight. Breastfeeding Medicine, 10(5), 246-252. http://dx.doi. org $/ 10.1089 /$ bfm.2014.0153

Brown, A., \& Lee, M. (2011). An exploration of the attitudes and experiences of mothers in the United Kingdom who chose to breastfeed exclusively for 6 months postpartum. Breastfeeding Medicine, 6(4), 197-204. http://dx.doi.org/10.1089/bfm.2010. $\underline{0097}$

Brown, A., Raynor, P., \& Lee, M. (2011a). Healthcare professionals' and mothers' perceptions of factors that influence decisions to breastfeed or formula feed infants: A comparative study. Journal of Advanced Nursing, 67(9), 1993-2003. http://dx.doi.org/10. 1111/j.1365-2648.2011.05647.x

Brown, A., Raynor, P., \& Lee, M. (2011b). Maternal control of child-feeding during breast and formula feeding in the first 6 months post-partum. Journal of Human Nutrition and Dietetics, 24(2), 177-186. http://dx.doi.org/10.1111/j.1365-277X.2010. $\underline{01145 . x}$ 
Brown, A., \& Lee, M. (2013). Breastfeeding is associated with a maternal feeding style low in control from birth. PLoS One, 8(1), e54229. http://dx.doi.org/10.1371/journal.pone.0054229

Brown, A., Rance, J., \& Bennett, P. (2016). Understanding the relationship between breastfeeding and postnatal depression: The role of pain and physical difficulties. Journal of Advanced Nursing, 72(2), 273-282. http://dx.doi.org/10.1111/jan.12832

Burns, E., Fenwick, J., Sheehan, A., \& Schmied, V. (2013). Mining for liquid gold: Midwifery language and practices associated with early breastfeeding support. Maternal $\mathbb{E}$ Child Nutrition, 9(1), 57-73. http://dx.doi.org/10.1111/j.1740-8709.2011. 00397.x

Cockerell, J. (2015). Viagra: Number of prescriptions for erectile dysfunction drugs rises by more than a quarter. The Independent. Retrieved from https://www.independent.co.uk/life-style/ health-and-families/health-news/viagra-number-of-prescriptionsfor-erectile-dysfunction-drugs-rises-by-more-than-a-quarter10372318.html

Craig, H. J., \& Dietsch, E. (2010). 'Too scary to think about': First time mothers' perceptions of the usefulness of antenatal breastfeeding education. Women and Birth, 23(4), 160-165. http://dx.doi.org/10.1016/j.wombi.2010.04.004

Crossley, M. L. (2009). Breastfeeding as a moral imperative: An autoethnographic study. Feminism $\mathcal{E}$ Psychology, 19(1), 71-87. http://dx.doi.org/10.1177/0959353508098620

Daglas, M., \& Antoniou, E. (2012). Cultural views and practices related to breastfeeding. Health Science Journal, 6(2).

Davim, R. M. B., Enders, B. C., \& Silva, R. A. Rda. (2010). Mothers' feelings about breastfeeding their premature babies in a rooming-in facility. Revista da Escola de Enfermagem da USP, 44(3), 713-718. http://dx.doi.org/10.1590/S0080$\underline{62342010000300023}$

Dennis, C. L., \& McQueen, K. (2009). The relationship between infant-feeding outcomes and postpartum depression: A qualitative systematic review. Pediatrics, 123(4), e736-e751. http://dx.doi.org/10.1542/peds.2008-1629

Díaz Meneses, G. (2013). Breastfeeding: An emotional instinct. Breastfeeding Medicine, 8(2), 191-197. http://dx.doi.org/10. $1089 / \mathrm{bfm} .2012 .0079$

Elmir, R., Schmied, V., Wilkes, L., \& Jackson, D. (2010). Women's perceptions and experiences of a traumatic birth: A metaethnography. Journal of Advanced Nursing, 66(10), 2142-2153. http://dx.doi.org/10.1111/j.1365-2648.2010.05391.x

Entwistle, F., Kendall, S., \& Mead, M. (2010). Breastfeeding support-the importance of self-efficacy for low-income women. Maternal $\mathcal{E}$ Child Nutrition, 6(3), 228-242. http://dx.doi.org/10. 1111/j.1740-8709.2009.00202.x

Fahlquist, J. N. (2016). Experience of non-breastfeeding mothers: Norms and ethically responsible risk communication. Nursing Ethics, 23(2), 231-241. http://dx.doi.org/10.1177/ $\underline{0969733014561913}$

Faircloth, C. (2013). Militant lactivism?: Attachment parenting and intensive motherhood in the UK and France. Berghahn Books.

Faircloth, C. R. (2010). 'If they want to risk the health and well-being of their child, that's up to them': Long-term breastfeeding, risk and maternal identity. Health, Risk
Eु Society, 12(4), 357-367. http://dx.doi.org/10.1080/ 13698571003789674

Flacking, R., Ewald, U., Nyqvist, K. H., \& Starrin, B. (2006). Trustful bonds: A key to "becoming a mother" and to reciprocal breastfeeding. Stories of mothers of very preterm infants at a neonatal unit. Social Science EF Medicine, 62(1), 70-80. http://dx. doi.org/10.1016/i.socscimed.2005.05.026

Gallup, G. G., Nathan Pipitone, R., Carrone, K. J., \& Leadholm, K. L. (2010). Bottle feeding simulates child loss: Postpartum depression and evolutionary medicine. Medical Hypotheses, 74(1), 174-176. http://dx.doi.org/10.1016/j.mehy.2009.07. $\underline{016}$

Gonidakis, F., Rabavilas, A. D., Varsou, E., Kreatsas, G., \& Christodoulou, G. N. (2008). A 6-month study of postpartum depression and related factors in Athens Greece. Comprehensive Psychiatry, 49(3), 275-282. http://dx.doi.org/10.1016/i. comppsych.2007.05.018

Grayson, J. (2016). Unlatched: The evolution of breastfeeding and the making of a controversy. New York, NY: Harper.

Gregory, E. F., Butz, A. M., Ghazarian, S. R., Gross, S. M., \& Johnson, S. B. (2015). Are unmet breastfeeding expectations associated with maternal depressive symptoms? Academic Pediatrics, 15(3), 319-325. http://dx.doi.org/10.1016/j.acap. 2014.12.003

Hall, W. A., \& Hauck, Y. (2007). Getting it right: Australian primiparas' views about breastfeeding: A quasi-experimental study. International Journal of Nursing Studies, 44(5), 786-795. http://dx.doi.org/10.1016/j.ijnurstu.2006.02.006

Hegney, D., Fallon, T., \& O’Brien, M. L. (2008). Against all odds: A retrospective case-controlled study of women who experienced extraordinary breastfeeding problems. Journal of Clinical Nursing, 17(9), 1182-1192. http://dx.doi.org/10.1111/j.1365-2702.2008. 02300.x

Henderson, A. (2011). Understanding the breast crawl: Implications for nursing practice. Nursing for Women's Health, 15(4), 296-307. http://dx.doi.org/10.1111/i.1751-486X.2011.01650.x

Ip, S., Chung, M., Raman, G., Trikalinos, T. A., \& Lau, J. (2009). A summary of the Agency for Healthcare Research and Quality's evidence report on breastfeeding in developed countries. Breastfeeding Medicine, 4 Suppl 1, S-17-10. http://dx.doi.org/10. $1089 / \mathrm{bfm} .2009 .0050$

Jung, C. (2015). Lactivism: How feminists and fundamentalists, hippies and yuppies, and physicians and politicians made breastfeeding big business and bad policy. New York: Basic Books.

Kendall-Tackett, K., Cong, Z., \& Hale, T. W. (2011). The effect of feeding method on sleep duration, maternal well-being, and postpartum depression. Clinical Lactation, 2(2), 22-26. http:// dx.doi.org/10.1891/215805311807011593

Knaak, S. J. (2010). Contextualising risk, constructing choice: Breastfeeding and good mothering in risk society. Health, Risk Eु Society, 12(4), 345-355. http://dx.doi.org/10.1080/ 13698571003789666

Labbok, M. (2008). Exploration of guilt among mothers who do not breastfeed: The physician's role. Journal of Human Lactation, 24(1), 80-84. http://dx.doi.org/10.1177/0890334407312002 
Latini, D. M., Penson, D. F., Colwell, H. H., Lubeck, D. P., Mehta, S. S., Henning, J. M., \& Lue, T. F. (2002). Psychological impact of erectile dysfunction: Validation of a new health related quality of life measure for patients with erectile dysfunction. The Journal of Urology, 168(5), 2086-2091. http://dx.doi.org/10. 1016/S0022-5347(05)64302-9

Lawrence, R. M., \& Lawrence, R. A. (2001). Given the benefits of breastfeeding, what contraindications exist? Pediatric Clinics of North America, 48(1), 235-251. http://dx.doi.org/10.1016/ S0031-3955(05)70297-2

Lee, E. (2007). Health, morality, and infant feeding: British mothers' experiences of formula milk use in the early weeks. Sociology of Health E Illness, 29(7), 1075-1090. http://dx.doi. org/10.1111/j.1467-9566.2007.01020.x

Lee, E., Bristow, J., Faircloth, C., \& Macvarish, J. (2014). Parenting culture studies. New York, NY: Springer Publishing.

Li, R., Fein, S. B., Chen, J., \& Grummer-Strawn, L. M. (2008). Why mothers stop breastfeeding: Mothers' self-reported reasons for stopping during the first year. Pediatrics, 122 Suppl 2, S69-S76. http://dx.doi.org/10.1542/peds.2008-1315i

Lööf-Johanson, M., Foldevi, M., \& Rudebeck, C. E. (2013). Breastfeeding as a specific value in women's lives: The experiences and decisions of breastfeeding women. Breastfeeding Medicine, 8(1), 38-44. http://dx.doi.org/10.1089/bfm.2012.0008

Manhire, K. M., Hagan, A. E., \& Floyd, S. A. (2007). A descriptive account of New Zealand mother's responses to open-ended questions on their breast feeding experiences. Midwifery, 23(4), 372-381. http://dx.doi.org/10.1016/j.midw.2006.01.002

Marshall, J. L., Godfrey, M., \& Renfrew, M. J. (2007). Being a 'good mother': Managing breastfeeding and merging identities. Social Science $\mathcal{E}$ Medicine, 65(10), 2147-2159. http://dx.doi.org/10. 1016/i.socscimed.2007.06.015

McAndrew, F., Thompson, J., Fellows, L., Large, A., Speed, M., \& Renfrew, M. J. (2012). Infant feeding survey 2010. Leeds, UK: Health and Social Care Information Centre.

Meedya, S., Fahy, K., \& Kable, A. (2010). Factors that positively influence breastfeeding duration to 6 months: A literature review. Women and Birth, 23(4), 135-145. http://dx.doi.org/10. 1016/j.wombi.2010.02.002

Neville, M. C., Morton, J., \& Umemura, S. (2001). Lactogenesis. The transition from pregnancy to lactation. Pediatric Clinics of North America, 48(1), 35-52.

Newby, R. M., \& Davies, P. S. (2016). Why do women stop breastfeeding? Results from a contemporary prospective study in a cohort of Australian women. European Journal of Clinical Nutrition, 70(12), 1428-1432. http://dx.doi.org/10.1038/ejcn. $\underline{2016.157}$

Palmér, L., Carlsson, G., Mollberg, M., \& Nyström, M. (2012). Severe breastfeeding difficulties: Existential lostness as a mother-Women's lived experiences of initiating breastfeeding under severe difficulties. International Journal of Qualitative Study of Health $\mathcal{E}$ Well-being, 7(1), 10846.

Pope, C. J., Mazmanian, D., Bédard, M., \& Sharma, V. (2016). Breastfeeding and postpartum depression: Assessing the influence of breastfeeding intention and other risk factors. Journal of Affective Disorders, 200, 45-50. http://dx.doi.org/10. 1016/j.jad.2016.04.014
Renfrew, M. J., McCormick, F. M., Wade, A., Quinn, B., \& Dowswell, T. (2012). Support for healthy breastfeeding mothers with healthy term babies. The Cochrane Database of Systematic Reviews, 5(5), CD001141. http://dx.doi.org/10.1002/14651858. CD001141.pub4

Righard, L., Alade, M., Harris, H., Colson, S. D., Meek, J. H., \& Hawdon, J. M. (1990). What babies know. The Lancet, 336, 1105-1107.

Robinson, C. (2016). Misshapen motherhood: Placing breastfeeding distress. Emotion, Space and Society.

Rollins, N. C., Bhandari, N., Hajeebhoy, N., Horton, S., Lutter, C. K., Martines, J. C., . . .\& Lancet Breastfeeding Series Group. (2016). Why invest, and what it will take to improve breastfeeding practices? The Lancet, 387(10017), 491-504. http://dx.doi.org/10.1016/S0140-6736(15)01044-2

Schmied, V., Beake, S., Sheehan, A., McCourt, C., \& Dykes, F. (2011). Women's perceptions and experiences of breastfeeding support: A metasynthesis. Birth, 38(1), 49-60. http://dx.doi. org/10.1111/i.1523-536X.2010.00446.X

Ryan, K., Bissell, P., \& Alexander, J. (2010). Moral work in women's narratives of breastfeeding. Social Science $\mathcal{E}$ Medicine, 70(6), 951-958. http://dx.doi.org/10.1016/j.socscimed.2009.11.023

Schmied, V., \& Barclay, L. (1999). Connection and pleasure, disruption and distress: Women's experience of breastfeeding. Journal of Human Lactation, 15(4), 325-334. http://dx.doi.org/ $\underline{10.1177 / 089033449901500410}$

Schmied, V., \& Lupton, D. (2001). Blurring the boundaries: Breastfeeding and maternal subjectivity. Sociology of Health $\mathbb{E}$ Illness, 23(2), 234-250. http://dx.doi.org/10.1111/1467-9566. $\underline{00249}$

Shaw, R. (2004). Performing breastfeeding: Embodiment, ethics and the maternal subject. Feminist Review, 78(1), 99-116. http://dx. doi.org/10.1057/palgrave.fr.9400186

Shepherd, L., Walbey, C., \& Lovell, B. (2017). The role of socialcognitive and emotional factors on exclusive breastfeeding duration. Journal of Human Lactation, 33(3), 606-613. http://dx. doi.org/10.1177/0890334417708187

Soterio-Pires, J. H., Hirotsu, C., Kim, L. J., Bittencourt, L., Tufik, S., \& Andersen, M. L. (2017). The interaction between erectile dysfunction complaints and depression in men: A crosssectional study about sleep, hormones and quality of life. International Journal of Impotence Research, 29(2), 70-75. http:// dx.doi.org/10.1038/ijir.2016.49

Sriraman, N. K., \& Kellams, A. (2016). Breastfeeding: What are the barriers? Why women struggle to achieve their goals. Journal of Women's Health, 25(7), 714-722. http://dx.doi.org/10.1089/ jwh.2014.5059

Taylor, E. N., \& Wallace, L. E. (2012). For shame: Feminism, breastfeeding advocacy, and maternal guilt. Hypatia, 27(1), 76-98. http://dx.doi.org/10.1111/j.1527-2001.2011.01238.x

Thomson, G., Ebisch-Burton, K., \& Flacking, R. (2015). Shame if you do-shame if you don't: Women's experiences of infant feeding. Maternal Eु Child Nutrition, 11(1), 33-46. http://dx.doi. org $/ 10.1111 / \mathrm{mcn} .12148$

Victora, C. G., Bahl, R., Barros, A. J., França, G. V., Horton, S., Krasevec, J., . . \& Lancet Breastfeeding Series Group. (2016). 
Breastfeeding in the 21st century: Epidemiology, mechanisms, and lifelong effect. The Lancet, 387(10017), 475-490. http://dx. doi.org/10.1016/S0140-6736(15)01024-7

Wolf, J. B. (2010). Is breast best?: Taking on the breastfeeding experts and the new high stakes of motherhood. New York: NYU Press.
Ystrom, E. (2012). Breastfeeding cessation and symptoms of anxiety and depression: A longitudinal cohort study. BMC Pregnancy and Childbirth, 12(1), 36. http://dx.doi.org/10.1186/1471-2393. $\underline{12-36}$

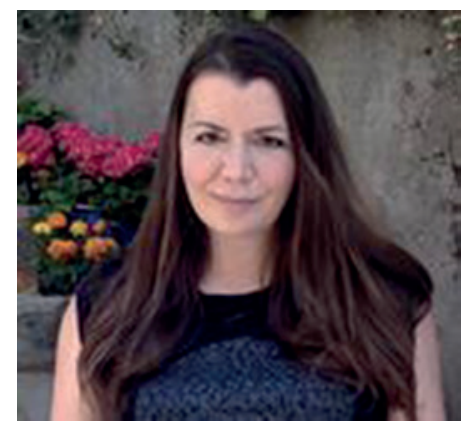

Amy Brown, $\mathrm{PhD}$, is based in the Department of Public Health, Policy and Social Sciences at Swansea University in the UK where she leads the MSc in Child Public Health. With a background in psychology, she first became interested in the many barriers women face when breastfeeding after having her first baby. Three babies and a $\mathrm{PhD}$ later she has spent the last 12 years exploring psychological, cultural, and societal barriers to breastfeeding, with an emphasis on understanding how we can better support women to breastfeed and subsequently raise breastfeeding rates. Her primary focus is how we can shift our perception of breastfeeding as an individual mothering issue, to a wider public health problem, with consideration how we can make societal changes to protect and encourage breastfeeding.

\section{Breastfeeding Accessories Market Trends Report}

Grand View Research has published a report entitled "Breastfeeding Accessories Market Size, Share \& Trends Analysis Report By Product (Nipple Care Products, Breast Shells, Breast Pads, Breastmilk Storage \& Feeding), By Region, And Segment Forecasts, 2018-2025": https://www.grandviewresearch.com/industryanalysis/breastfeeding-accessories-market. The report includes background on breastfeeding accessories, as well as product and regional insights. The global breastfeeding accessories market size was valued at USD 1.2 billion in 2016 and is estimated to expand at a Compound Annual Growth Rate of $7.9 \%$ during the forecast period.

Source: USBC 